\title{
Quality characteristics of grain syrups containing ginger (Zingiber officinale)
}

\author{
Sun-Dae SHIN ${ }^{1}$, Myung-Sook LEE ${ }^{1}$, Je-Hyuk LEE ${ }^{1 \star ~(C) ~}$
}

\begin{abstract}
Korean traditional grain syrup (Jocheong) is prepared by removing moisture from saccharified-starch suspensions. The addition of ginger (0-6.4\%) to grain syrup did not change the solid content (moisture content) or sugar content. The grain syrup resulted in increased $\mathrm{Mn}, \mathrm{P}, \mathrm{Zn}, \mathrm{Na}, \mathrm{Mg}, \mathrm{Ca}$, and $\mathrm{P}$ contents upon addition of ginger. The ginger-added grain syrup had increased total phenolic content and 2,2-diphenyl-1-picrylhydrazyl (DPPH) and 2,2'-azino-bis(3-ethylbenzothiazoline-6-sulfonic acid (ABTS) radical-scavenging activities, compared with normal grain syrup. Staphylococcus aureus exhibited slight growth inhibition in medium containing ginger-supplemented grain syrup and the fungi did not grow at all on ginger (3.2\%)-added grain syrup during 6 days of incubation. The addition of ginger may contribute to improving the nutritional quality of grain syrups, enhancing health functions and extending the storage period.
\end{abstract}

Keywords: antibacterial activity; antioxidant activity; mineral content; shelf-life; total phenolic content; grain syrup.

Practical Application: Improvement of nutritional and functional properties of grain syrup by addition of ginger.

\section{Introduction}

The highly viscous Korean grain syrup (Jocheong) is prepared by removing moisture from a saccharified-starch suspension (Sikhye, a traditional Korean drink) by heating. The saccharifiedstarch suspension is made from various starches saccharified by malting. Grain syrup has been used as a sweetener and snack for a long time in Korea and has also been used in the manufacture of several traditional foods such as Yukwa (fried glutinous rice cake). In addition, in order to enhance palatability and add characteristic taste and aroma, grain syrup has been manufactured by adding various ingredients such as corn, pumpkin, and pheasant meat.

The primary focus in research regarding grain syrup has been on improving manufacturing processes. The purpose of these studies was to improve and optimize such manufacturing processes by standardizing and improving saccharifying enzymes to be suitable for large-scale grain syrup production. Several studies concerning the preparation of grain syrup using microwaves (Kim \& Kim, 1985) and optimum saccharification conditions (Kim \& Kang, 1994) and quality characteristics (Rhee et al., 1992) dependent on storage temperature have been conducted. Another focus of grain syrup research is to impart new flavor and taste to sweeten the grain syrup by adding various subsidiary materials; however, scientific research data are currently insufficient. Grain syrups containing sweet persimmon (Bae et al., 2001), shiitake mushroom powder (Park \& Na, 2005), apple (Yang \& Ryu, 2010), steamed garlic powder (Kang \& Shin, 2012), and Gastrodia elata liquid extract (Lee, 2015) have been reported.

Ginger (Zingiber officinale) has been used for a long time as a spice to enhance the flavor and taste of food in many countries. Ginger contains various hydrocarbons, ketones, alcohols, and volatile aromatic ingredients, such as zingiberene and $\gamma$-cardinen, and other ingredients that impart a spicy ginger taste such as gingerol, shogaol, and zingerone (Ekundayo et al., 1988; Ravi Kiran et al., 2013; Yamamoto-Ribeiro et al., 2013). These compounds have been reported to suppress odor, improve food flavor, and increase the shelf-life of foodstuffs (Cao et al., 2013; Ahmed et al., 2019). Steamed ginger and ginger oleoresin exert chemical free-radical-scavenging activity in vitro (Stoilova et al., 2007; Tohma et al., 2017; Kim et al., 2018). Additionally, ginger extract improved antioxidant capacity by reducing malondialdehyde (MDA) levels in body fluids and by increasing the production of antioxidant enzymes superoxide dismutase (SOD) and catalase in formalin-treated rats in vivo (Rasyidah et al., 2014).

In Korea, ginger has traditionally been added to enhance the flavor of grain syrups, but there are few scientific studies or reports regarding this. The purpose of this study was to evaluate the effects of addition of ginger on mineral levels, antioxidant properties, and antibacterial activities of grain syrups.

\section{Materials and Methods}

\subsection{Experimental materials}

Non-glutinous rice (Oryza sativa) was harvested in Seosan, Chungcheongnam-do, Korea, in 2017 and polished in January 2018. Malt was purchased from Cheonan, Chungcheongnamdo, Korea, in 2017. Ginger (Zingiber offcinale), produced domestically in 2017, was processed to juice using a grinder (DA280-S, Daesung Artlon Co., Ltd, Paju, Korea). Other firstgrade reagents were purchased from Sigma (Sigma-Aldrich Co., St. Louis, MO, USA). 


\subsection{Preparation of grain syrup}

Rice (1 kg) was washed five times with tap water, soaked for $4 \mathrm{~h}$, and cooked to hard-steamed rice using an electric rice cooker (CR-3021V, Yangsang, Korea). Hard-steamed rice was mixed with water $(4 \mathrm{~L})$ and malt powder $(200 \mathrm{~g})$ and was saccharified by malting at $75^{\circ} \mathrm{C}$ for $14 \mathrm{~h}$. The saccharified solution was filtered through a cotton cloth and mixed with the ginger juices. The mixture was slowly stirred at $70^{\circ} \mathrm{C}$ for $2 \mathrm{~h}$ to remove moisture until the mass of the mixture was approximately $1,300 \mathrm{~g}$ and then cooled to room temperature to prepare the grain syrup.

\subsection{Determination of solid and sugar contents}

The solid content in the grain syrup was measured by drying under atmospheric pressure (Association of Official Analytical Chemists, 1990). The grain syrup (10 g) was dried in a dry oven (OF-11E Forced Convection Oven, Lab Companion, Daejeon, Korea) at $105^{\circ} \mathrm{C}$ for $48 \mathrm{~h}$. Sugar content (Brix\%) was measured using a portable refractometer (N.O.W Tokyo Hand Refractometer, Tokyo, Japan) after dissolving the grain syrup $(50 \mathrm{~g})$ in $100 \mathrm{~mL}$ of distilled water.

\subsection{Determination of reducing sugars and dextrose equivalents}

Reducing sugar levels in the grain syrup were analyzed using the 3,5-dinitrosalicylic acid (DNS) method (Miller, 1959). DNS reagent $(1 \%, 3 \mathrm{~mL})$ was added to $1 \mathrm{~mL}$ of sample, which was prepared by dissolving $1 \mathrm{~g}$ of the grain syrup in $100 \mathrm{~mL}$ of water, and the mixture was then heated at $90^{\circ} \mathrm{C}$ for $5 \mathrm{~min}$ and cooled rapidly. The optical absorbance of the reactants was measured at $550 \mathrm{~nm}$ using a spectrophotometer (V-1100D, Labinno Co., Japan). The amount of reducing sugar was calculated from a standard curve using maltose as a reference. In addition, the dextrose equivalent (DE, \%) was calculated using the following formula (Korea Food and Drug Administration, 2006):

$\mathrm{DE}(\%)=($ Reducing sugar content, $\%) /($ Solid content, $\%) \times 100$

\subsection{Analysis of minerals}

Mineral (Na, Mg, K, Ca, Mn, Si, Fe, Zn, and Pd) contents in the grain syrup were analyzed using an inductively-coupled plasma-optical emission spectrometer (ICP-OES; GBC IntegraXMP, Braeside, Australia). The grain syrup ( $5 \mathrm{~g}$ ) was completely dissolved in $10 \mathrm{~mL}$ of $1 \% \mathrm{HNO}_{3}$ using a microwave oven, diluted to $50 \mathrm{~mL}$, and then used as an analysis sample. Standard materials (Kanto Chemical Co., Tokyo, Japan) were diluted with $1 \% \mathrm{HNO}_{3}$ to quantify mineral contents.

\subsection{Determination of total phenolic content}

Total phenolic content in the grain syrup was measured using a partially-modified Folin-Ciocalteu method (Oh et al., 2004). Grain syrup (0.05 g) was mixed with $1 \mathrm{~mL}$ of $1 \mathrm{~N}$ FolinCiocalteu's phenol reagent, left at room temperature for $5 \mathrm{~min}$, and then mixed with $2 \mathrm{~mL}$ of $20 \%(\mathrm{w} / \mathrm{v}) \mathrm{Na}_{2} \mathrm{CO}_{3}$. The optical absorbance of the supernatant was measured at $765 \mathrm{~nm}$ using a spectrophotometer. The total phenolic content was expressed in mg gallic acid equivalents (GAE)/g dry weight (dw) using gallic acid as a standard.

\subsection{Determination of antioxidant activity}

2,2-Diphenyl-1-picrylhydrazyl (DPPH) radical-scavenging activity was determined using the method of Lee et al. (Lee et al., $2005)$ with certain modifications. The grain syrup $(0.2 \mathrm{~mL}$ in methanol) was mixed with $4 \mathrm{~mL}$ of methanol and $0.5 \mathrm{~mL}$ of DPPH solution $(1 \mathrm{mM})$. The mixture was vortexed vigorously for $15 \mathrm{~s}$ and left at room temperature for $30 \mathrm{~min}$. Then, the optical absorbance of the solution was measured at $517 \mathrm{~nm}$ using a spectrophotometer. 2,2'-Azino-bis(3-ethylbenzothiazoline-6-sulfonic acid (ABTS) radical-scavenging activity was determined using a partially modified method described by Thaipong et al. (2006). The ABTS radical solution was prepared by dissolving $2.45 \mathrm{mM}$ potassium persulfate and $7 \mathrm{mM}$ ABTS in phosphate-buffered saline $(\mathrm{pH} 7.4)$ and was left in the dark at room temperature for $24 \mathrm{~h}$ to generate radicals. Then, $10 \mu \mathrm{L}$ of grain syrup was added to $190 \mu \mathrm{L}$ of ABTS solution and reacted in the dark for $30 \mathrm{~min}$. Changes in optical absorbance of the reactants were measured using a spectrophotometer at $734 \mathrm{~nm}$. The radical-scavenging activity was expressed as $\mathrm{mg}$ Trolox equivalents (TE)/g dw.

\subsection{Determination of antibacterial activity}

Antibacterial activity of the grain syrup was measured by growth inhibition assays involving Staphylococcus aureus (S. aureus), a food-poisoning bacterium. Precultured S. aereus $\left(0.5 \mathrm{~mL}, \mathrm{OD}_{600}=0.7\right)$ was inoculated into $100 \mathrm{~mL}$ of nutrient broth (beef extract $3.0 \mathrm{~g} / \mathrm{L}$ and peptone $5.0 \mathrm{~g} / \mathrm{L}$ ) containing $25 \mathrm{~g}$ of the grain syrup and cultured in an incubator (SIF6000R, Lab Companion, Daejeon, Korea) with $150 \mathrm{rpm}$ rotary agitation at $37^{\circ} \mathrm{C}$ for $24 \mathrm{~h}$. The growth of $S$. aureus was measured using optical absorbance at $600 \mathrm{~nm}$ with a spectrophotometer. In addition, $10 \mathrm{~g}$ of grain syrup containing ginger was placed in Petri dishes and incubated at $25^{\circ} \mathrm{C}$ for 6 days. The effect of ginger on extending the storage period of the grain syrup was evaluated by visually observing the growth of fungi for 6 days.

\subsection{Statistical analysis}

All experiments were repeated at least three times, and data are expressed as means and standard deviation and were analyzed using one-way analysis of variance (ANOVA) and Duncan's multiple comparison test. SPSS v.24.0 (IBM SPSS Inc., Chicago, IL, USA) was used for statistical analysis, and $p<0.05$ was considered to be statistically significant.

\section{Results and Discussion}

\subsection{Sugar content in grain syrup containing ginger}

The solid content of normal grain syrup was approximately $59.62 \%$, and the addition of ginger $(0-6.4 \%)$ did not affect this (Table 1). The sugar content (Brix\%) of normal grain syrup was approximately $62.67 \mathrm{Brix} \%$, and values for grain syrups containing $3.2 \%, 4.8 \%$, and $6.4 \%$ of ginger were determined to be $59.67 \%, 63.33 \%$, and $62.67 \mathrm{Brix} \%$, respectively (Table 1 ). 
However, no significant difference was observed in the sugar content of ginger-supplemented grain syrup, except for the grain syrup containing $4.8 \%$ ginger. In addition, normal grain syrup had approximately $32.45 \%(\mathrm{w} / \mathrm{w})$ of reducing sugars, and the addition of $3.2 \%, 4.8 \%$, and $6.4 \%$ ginger contributed approximately $25.35 \%, 34.16 \%$, and $35.63 \%(\mathrm{w} / \mathrm{w})$ reducing sugars to the grain syrups, respectively. Reducing sugar levels in the grain syrup increased significantly with the addition of ginger, excluding the $3.2 \%$ ginger-grain syrup sample. The content of reducing sugars in the grain syrup refers to the contents of glucose, fructose, and maltose, but not of sucrose, which is a non-reducing sugar (Yang \& Ryu, 2010). Ginger carbohydrates consist of approximately $40-60 \%$ of starch and $2.2 \%(\mathrm{w} / \mathrm{w})$ of reducing sugars (Lee et al., 2014). The addition of ginger to the grain syrup appears to have contributed to a significant increase in reducing sugar content in the grain syrup, although this was a minor amount. The DE of normal grain syrup was $54.43 \%$, and the $3.2 \%, 4.8 \%$, and $6.4 \%$ ginger-added grain syrups had $44.67 \%, 57.75 \%$, and $61.05 \% \mathrm{DE}$, respectively. The higher DE of the grain syrup indicates greater saccharification of starch, and the sweetness of the grain syrup was elevated with increasing DE.

\subsection{Mineral content in grain syrup containing ginger}

The mineral contents, including of $\mathrm{Na}, \mathrm{Mg}, \mathrm{K}$, and $\mathrm{Ca}$, in ginger-supplemented grain syrups are shown in Table 2. Normal grain syrup contained $\mathrm{P}, \mathrm{Mg}, \mathrm{Ca}$, and $\mathrm{Si}$ at $811.62,169.05$, 128.92 , and $187.48 \mu \mathrm{g} / \mathrm{g}$, respectively. Fe $(3.10 \mu \mathrm{g} / \mathrm{g})$ and $\mathrm{Zn}$ $(2.37 \mu \mathrm{g} / \mathrm{g})$ contents were relatively low in the normal grain syrup. The addition of ginger to the grain syrup increased the mineral contents dramatically, excluding of Si and Fe. Mn, P, and $\mathrm{Zn}$ contents were increased by $394.2 \%, 122.16 \%$, and $115.19 \%$ in the ginger (6.4\%)-added grain syrup, respectively. Additionally, the contents of $\mathrm{Na}, \mathrm{Mg}$, $\mathrm{K}$, and $\mathrm{Ca}$ in the ginger-supplemented grain syrup increased by $7.8-57.1 \%$. On the other hand, Si and Fe levels in $6.4 \%$ ginger-added grain syrup were decreased by $38.50 \%$ and $12.26 \%$, respectively. The addition of ginger to grain syrup may greatly improve the mineral qualities and nutritional properties of grain syrups.

\subsection{Total phenolic content (TPC) in grain syrup containing ginger}

TPCs in normal grain syrup were approximately $687.71 \mu \mathrm{g}$ GAE/g. TPC in the grain syrup increased to approximately $897.13,1009.58$, and $1171.67 \mu \mathrm{g} \mathrm{GAE} / \mathrm{g}$ with addition of $3.2 \%$, $4.8 \%$, and $6.4 \%$ ginger, respectively (Table 3 ). In the case of $6.4 \%$ ginger-supplemented grain syrup, the TPC in the grain syrup was increased to approximately $70.4 \%$ as compared to the normal grain syrup. TPC of grain syrups was reported to be $0.5-7.3 \mathrm{mg}$ $\mathrm{GAE} / \mathrm{g}$, depending on the type and amount of grains used in the manufacture of the syrup (Yang \& Ryu, 2010; Lee et al., 2012; Lee,

Table 1. Solid content, sugar content, reducing sugar content, and dextrose equivalent in various grain syrups supplemented with ginger.

\begin{tabular}{ccccc}
\hline Grain syrup ${ }^{1)}$ & Solid content $^{2)}(\%)$ & Sugar content (Brix\%) & Reducing sugar (w/w, \%) & Dextrose equivalent $(\mathrm{DE})(\%)^{3)}$ \\
\hline A & $59.62 \pm 0.31^{4) \mathrm{a}}$ & $62.67 \pm 0.58^{\mathrm{a}}$ & $32.45 \pm 0.25^{3), \mathrm{c}}$ & $54.43 \pm 5.42^{\mathrm{c}}$ \\
B & $56.76 \pm 0.55^{\mathrm{b}}$ & $59.67 \pm 0.58^{\mathrm{b}}$ & $25.35 \pm 0.63^{\mathrm{d}}$ & $44.67 \pm 7.21^{\mathrm{d}}$ \\
C & $59.15 \pm 0.30^{\mathrm{a}}$ & $63.33 \pm 0.29^{\mathrm{a}}$ & $34.16 \pm 0.03^{\mathrm{b}}$ & $57.75 \pm 2.19^{\mathrm{b}}$ \\
D & $58.38 \pm 1.40^{\mathrm{a}}$ & $62.67 \pm 0.58^{\mathrm{a}}$ & $35.63 \pm 0.30^{\mathrm{a}}$ & $61.05 \pm 1.93^{\mathrm{a}}$ \\
\hline
\end{tabular}

1) A: Grain syrup without ginger, B: Grain syrup with ginger (3.2\%), C: Grain syrup with ginger (4.8\%), D: Grain syrup with ginger (6.4\%); ${ }^{2}$ Solid content (\%) = [(solid content (g) after drying/sample $(\mathrm{g})] \times 100 ;{ }^{3)}$ D.E. $(\%)=[$ Reducing sugar content $(\%) /$ Solid content $(\%)] \times 100 ;{ }^{4)}$ Each value represents means \pm SD. ${ }^{\mathrm{a}, \mathrm{b}}$ Means with different superscripts in the same column indicate statistically significant difference $(p<0.05)$ by Duncan's multiple range test.

Table 2. Mineral contents in various grain syrups supplemented with ginger.

\begin{tabular}{|c|c|c|c|c|c|c|c|c|c|}
\hline \multirow{2}{*}{ Grain syrup ${ }^{1)}$} & \multicolumn{9}{|c|}{ Mineral content $(\mu \mathrm{g} / \mathrm{g})^{2)}$} \\
\hline & $\mathrm{Na}$ & $\mathrm{Mg}$ & $\mathrm{K}$ & $\mathrm{Ca}$ & $\mathrm{Mn}$ & $\mathrm{Si}$ & $\mathrm{Fe}$ & $\mathrm{Zn}$ & $\mathrm{P}$ \\
\hline A & $50.87 \pm 0.11^{2), d}$ & $169.05 \pm 1.68^{\mathrm{d}}$ & $33.66 \pm 0.05^{\mathrm{d}}$ & $128.92 \pm 1.62^{b}$ & $1.38 \pm 0.04^{\mathrm{d}}$ & $187.48 \pm 1.63^{\mathrm{a}}$ & $3.10 \pm 0.06^{\mathrm{b}}$ & $2.37 \pm 0.05^{\mathrm{d}}$ & $811.62 \pm 9.04^{d}$ \\
\hline B & $\begin{array}{r}56.98 \pm 0.51^{\mathrm{c}} \\
(\boldsymbol{\Delta} 12.01 \%)\end{array}$ & $\begin{array}{r}212.27 \pm 1.18^{c} \\
(\mathbf{\Delta} 25.57 \%)\end{array}$ & $\begin{array}{r}58.73 \pm 0.51^{c} \\
(\mathbf{\Delta} 74.48 \%)\end{array}$ & $\begin{array}{c}139.23 \pm 1.37^{\mathrm{a}} \\
(\boldsymbol{\Delta} 8.00 \%)\end{array}$ & $\begin{array}{l}7.28 \pm 0.10^{\mathrm{a}} \\
(\mathbf{\Delta} 427.54 \%)\end{array}$ & $\begin{array}{c}184.05 \pm 2.18^{\mathrm{b}} \\
\quad(\nabla 1.83 \%)\end{array}$ & $\begin{array}{c}2.56 \pm 0.05^{\mathrm{d}} \\
(\nabla 17.42 \%)\end{array}$ & $\begin{array}{l}4.31 \pm 0.02^{c} \\
(\mathbf{\Delta} 81.86 \%)\end{array}$ & $\begin{array}{c}970.97 \pm 8.97^{c} \\
(\boldsymbol{\Delta} 19.63 \%)\end{array}$ \\
\hline $\mathrm{C}$ & $\begin{array}{r}71.10 \pm 1.98^{\mathrm{a}} \\
(\boldsymbol{\Delta} 37.77 \%)\end{array}$ & $\begin{array}{c}244.21 \pm 3.85^{\mathrm{b}} \\
(\boldsymbol{\Delta} 44.46 \%)\end{array}$ & $\begin{array}{r}64.35 \pm 0.78^{\mathrm{b}} \\
(\boldsymbol{\Delta} 91.18 \%)\end{array}$ & $\begin{array}{c}140.41 \pm 1.75^{\mathrm{a}} \\
(\boldsymbol{\Delta} 8.91 \%)\end{array}$ & $\begin{array}{l}4.99 \pm 0.07^{c} \\
(\mathbf{\Delta} 261.59 \%)\end{array}$ & $\begin{array}{c}108.44 \pm 1.07^{\mathrm{d}} \\
(\nabla 42.16 \%)\end{array}$ & $\begin{array}{c}3.84 \pm 0.03^{\mathrm{a}} \\
(\mathbf{\Delta} 23.87 \%)\end{array}$ & $\begin{array}{l}4.76 \pm 0.07^{\mathrm{b}} \\
(\boldsymbol{\Delta} 100.84 \%)\end{array}$ & $\begin{array}{c}1051.92 \pm 5.44^{\mathrm{b}} \\
(\boldsymbol{\Delta} 29.61 \%)\end{array}$ \\
\hline $\mathrm{D}$ & $\begin{array}{r}67.18 \pm 1.24^{\mathrm{b}} \\
(\boldsymbol{\Delta} 32.06 \%)\end{array}$ & $\begin{array}{r}265.57 \pm 0.54^{\mathrm{a}} \\
(\boldsymbol{\Delta} 57.10 \%)\end{array}$ & $\begin{array}{r}74.78 \pm 0.63^{\mathrm{a}} \\
(\boldsymbol{\Delta} 122.16 \%)\end{array}$ & $\begin{array}{c}138.99 \pm 1.02^{\mathrm{a}} \\
(\boldsymbol{\Delta} 7.81 \%)\end{array}$ & $\begin{array}{l}6.82 \pm 0.09^{\mathrm{b}} \\
(\boldsymbol{\Delta} 394.20 \%)\end{array}$ & $\begin{array}{r}115.30 \pm 1.25^{c} \\
(\nabla 38.50 \%)\end{array}$ & $\begin{array}{l}2.72 \pm 0.02^{c} \\
(\nabla 12.26 \%)\end{array}$ & $\begin{array}{l}5.10 \pm 0.08^{\mathrm{a}} \\
(\boldsymbol{\Delta} 115.19 \%)\end{array}$ & $\begin{array}{c}1089.25 \pm 4.76^{\mathrm{a}} \\
(\boldsymbol{\Delta} 34.21 \%)\end{array}$ \\
\hline
\end{tabular}

Not Reported ${ }^{\text {a-d }}$ Means with different superscripts in the same column indicate statistically significantly differences at $p<0.05$ by Duncan's multiple range test.

Table 3. Total phenolic compound contents and DPPH and ABTS radical-scavenging activities in various grain syrups with added ginger

\begin{tabular}{cccc}
\hline Grain syrup $^{1)}$ & Total phenolic compound $(\mu \mathrm{g} \mathrm{GAE} / \mathrm{g})$ & DPPH $(\mu \mathrm{g}$ TE/g) & ABTS $(\mu \mathrm{g}$ TE/g) \\
\hline A & $687.71 \pm 53.40^{2), \mathrm{d}}$ & $378.85 \pm 9.38^{2), \mathrm{d}}$ & $1182.50 \pm 55.28^{\mathrm{c}}$ \\
B & $897.13 \pm 5.34^{\mathrm{c}}$ & $501.77 \pm 17.14^{\mathrm{c}}$ & $1406.25 \pm 43.75^{\mathrm{b}}$ \\
C & $1009.58 \pm 18.07^{\mathrm{b}}$ & $548.85 \pm 9.28^{\mathrm{b}}$ & $1649.58 \pm 22.37^{\mathrm{a}}$ \\
D & $1171.67 \pm 2.53^{\mathrm{a}}$ & $621.56 \pm 2.17^{\mathrm{a}}$ & $1755.83 \pm 104.35^{\mathrm{a}}$ \\
\hline
\end{tabular}

1) A: Grain syrup without ginger, B: Grain syrup with ginger (3.2\%), C: Grain syrup with ginger (4.8\%), D: Grain syrup with ginger (6.4\%) ${ }^{2)}$ Each value represents the mean \pm SD. a-d Means with different superscripts in the same column indicate statistically significantly difference at $p<0.05$ by Duncan's multiple range test. 
(A)

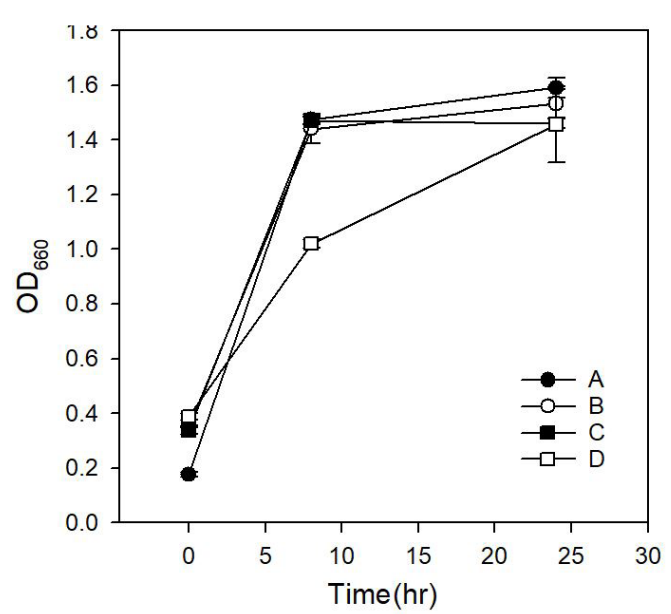

(B)

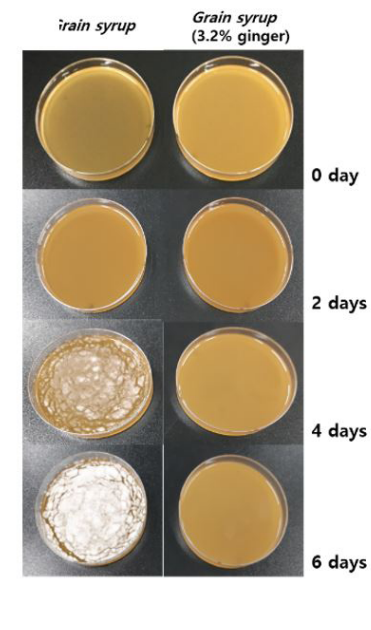

Figure 1. Antimicrobial activity of various grain syrups supplemented with ginger. (A) Antibacterial activity against $S$. aureus, A: Grain syrup without ginger, B: Grain syrup with ginger (3.2\%), C: Grain syrup with ginger (4.8\%), D: Grain syrup with ginger (6.4\%), (B) Antifungal activity.

2015; Lee \& Lee, 2015). Ginger has approximately 150-200 mg GAE/g of TPC, which is approximately 200-times higher than that of normal grain syrup (Lee et al., 2014). Hence, TPCs in the grain syrups are anticipated to increase dramatically, depending on the amount of ginger added. The increased TPC content in grain syrup after adding ginger may impart antioxidant activity to otherwise normal grain syrup.

\subsection{Antioxidant activity of grain syrup containing ginger}

The antioxidant activity of ginger-supplemented grain syrups was analyzed by DPPH and ABTS free-radical-scavenging activity assays, as shown in Table 3. DPPH and ABTS free-radicalscavenging activities in normal grain syrup were approximately 378.85 and $1182.50 \mu \mathrm{g} \mathrm{TE} / \mathrm{g}$, respectively. DPPH radicalscavenging activity in $6.4 \%$ ginger-supplemented grain syrup was approximately $621.56 \mu \mathrm{g} \mathrm{TE} / \mathrm{g}$, representing an approximate $64 \%$ increase in antioxidant activity as compared to normal grain syrup. In addition, the ABTS radical-scavenging activity of ginger (6.4\%)-supplemented grain syrup was approximately $1755.83 \mu \mathrm{g} \mathrm{TE} / \mathrm{g}$, which was elevated by $48 \%$ as compared to normal grain syrup.

\subsection{Antibacterial activity of grain syrup containing ginger}

The antibacterial activity of grain syrup containing ginger is shown in Figure 1. Growth inhibitory effects on S. aureus were investigated using a medium containing ginger-supplemented grain syrup (Figure 1A). S. aureus exhibited approximately $30.62 \%$ and $8.17 \%$ growth inhibition in medium containing ginger (6.4\%)-supplemented grain syrup after 7 and $24 \mathrm{~h}$ of incubation, respectively. In addition, the grain syrup (10 g) was maintained in a Petri dish at $30^{\circ} \mathrm{C}$ for 6 days to confirm spoilage or otherwise (Figure 1B). Small white mold mycelia began to grow on the surface of the normal grain syrup from day 2 of incubation. By day 4, the white fungi grew to occupy approximately $20-30 \%$ of the Petri dish, and by day 6 , the fungi were confluent on the surface of the Petri dish containing normal grain syrup. However, fungi exhibited no growth whatsoever on grain syrup medium containing 3.2\% ginger after incubation for 6 days (Figure 1B).

Ginger has been reported to exert antibacterial activity against food-poisoning bacteria such as S. enteritidis, Escherichia coli O157: H7, Listeria monocytogenes (Hara-kudo et al., 2004), Baccilus subtilis, and S. aureus (Sethi et al., 2013). Additionally, gingerol, shogoal, zingerone, and zerumbone present in ginger exhibit antibacterial activities (Rahmani et al., 2014). Therefore, the addition of ginger to grain syrup may extend the shelf-life of grain syrup by inhibiting the growth of food-poisoning bacteria.

\section{Conclusions}

Slight changes in reducing sugar content and DE after ginger was added to grain syrups did not alter sugar characteristics. The addition of ginger to grain syrups increased $\mathrm{Mn}, \mathrm{K}$, and Zn contents, TPC, and antioxidant activities of the grain syrup. As a consequence, the addition of ginger to grain syrups may contribute to improving the mineral qualities of such syrups, enhance their antioxidant activities, and prolong storage half-life.

\section{Acknowledgements}

This work was supported by a research grant from the Kongju National University in 2020.

\section{References}

Ahmed, E. S. S., Shehata, M. G., Abd-Rabou, H. S., \& El-Menshawy, H. (2019). Extend shelf-life of vacuum-packaged herring fish fillets using garlic and ginger extracts. Journal of Pure \& Applied Microbiology, 13(3), 1571-1581. http://dx.doi.org/10.22207/JPAM.13.3.30.

Association of Official Analytical Chemists - AOAC. (1990). Official Methods of Analysis of AOAC Intl (15. ed.). Washington, DC: AOAC.

Bae, S. M., Park, K. J., Shin, D. J., Hwang, Y. I., \& Lee, S. C. (2001). Preparation and characterization of Jochung with sweet persimmons. 
Journal of the Korean Society of Agricultural Chemistry and Biotechnology, 44(2), 88-81.

Cao, Y., Gu, W., Zhang, J., Chu, Y., Ye, X., Hu, Y., \& Chen, J. (2013). Effects of chitosan, aqueous extract of ginger, onion and garlic on quality and shelf life of stewed-pork during refrigerated storage. Food Chemistry, 141(3), 1655-1660. http://dx.doi.org/10.1016/j. foodchem.2013.04.084. PMid:23870874.

Ekundayo, O., Laakso, I., \& Hiltunen, R. (1988). Composition of ginger (Zingiber officinale roscoe) volatile oils from Nigeria. Flavour and Fragrance Journal, 3(2), 85-90. http://dx.doi.org/10.1002/ffj.2730030207.

Hara-kudo, Y., Kobayashi, A., Sugita-Konishi, Y., \& Kondo, K. (2004). Antibacterial activity of plants used in cooking for aroma and taste. Journal of Food Protection, 67(12), 2820-2824. http://dx.doi. org/10.4315/0362-028X-67.12.2820. PMid:15633695.

Kang, M. J., \& Shin, J. H. (2012). Quality characteristics of Jochung containing various level of steamed garlic powder. Korean Journal of Food and Cookery Science, 28(6), 865-870. http://dx.doi.org/10.9724/ kfcs.2012.28.6.865.

Kim, H. J., Kim, B. K., Mun, E. G., Jeong, S. Y., \& Cha, Y. S. (2018). The antioxidant activity of steamed ginger and its protective effects on obesity induced by high-fat diet in C57BL/6J mice. Nutrition Research and Practice, 12(6), 503-511. http://dx.doi.org/10.4162/ nrp.2018.12.6.503. PMid:30515278.

Kim, H. S., \& Kang, Y. J. (1994). Optimal condition of saccharification for a traditional malt syrup in Cheju. Korean Journal of Food Science Technology, 26(6), 659-664. http://dx.doi.org/10.9721/ KJFST.2011.43.6.659.

Kim, T. H., \& Kim, H. J. (1985). A study on the recipe and the characteristic of Yeots by microwave oven. Journal of Korean Home Economics Association, 23(3), 55-61.

Korea Food and Drug Administration - KFDA. (2006). Food Code. Korea, Seoul, Korea: Food and Drug Administration.

Lee, E. J., Kim, K. S., Jung, H. Y., Kim, D. H., \& Jang, H. D. (2005). Antioxidant activities of garlic (Allum sativum L.) with growing districts. Food Science and Biotechnology, 14(1), 123-130. http:// dx.doi.org/10.1007/s10068-011-0017-6.

Lee, H., Lee, J., Park, C., Ra, K., Ha, J., Cha, M., Kim, S., Choi, Y., Hwang, J., \& Nam, J. (2014). Physicochemical properties and antioxidant capacities of different parts of ginger (Zingiber officinale Roscoe). Journal of the Korean Society of Food Science and Nutrition, 43(9), 1369-1379. http://dx.doi.org/10.3746/jkfn.2014.43.9.1369.

Lee, J. E., Choi, Y. H., Cho, M. G., Park, S. Y., \& Kim, E. M. (2012). Characteristics of Jochung by wet-milled rice flour and steamed rice. Korean Journal of Food and Nutrition, 25(3), 637-643. http:// dx.doi.org/10.9799/ksfan.2012.25.3.637.

Lee, K. W., \& Lee, M. Y. (2015). Quality characteristics of Gastrodia elata powder Jochung with antioxidant activity. Journal of the Korean Society of Food Culture, 30(5), 656-666. http://dx.doi.org/10.7318/ KJFC/2015.30.5.656.

Lee, M. Y. (2015). Antioxidant activity and quality characteristics of non-glutinous rice porridge Jochung with added Gastrodia elata extract. Korean Journal of Food and Cookery Science, 31(5), 557-564. http://dx.doi.org/10.9724/kfcs.2015.31.5.557.
Miller, G. L. (1959). Use of dinitrosalicylic acid reagent for determination of reducing sugar. Analytical Chemistry, 31(3), 426-428. http://dx.doi. org/10.1021/ac60147a030.

Oh, P. S., Lee, S. J., \& Lim, K. T. (2004). Antioxidative activity of 90 $\mathrm{kDa}$ glycoprotein isolated from Opuntia ficus-indica var. saboten Makino. Food Science and Biotechnology, 13(6), 781-789.

Park, J. S., \& Na, H. S. (2005). Quality characteristics of Jochung containing various level of Letinus edodes powder. Korean Journal of Food Science Technology, 37(5), 768-775.

Rahmani, A. H., Shabrmi, F. M., \& Aly, S. M. (2014). Active ingredients of ginger as potential candidates in the prevention and treatment of diseases via modulation of biological activities. International Journal of Physiology, Pathophysiology and Pharmacology, 6(2), 125-136. PMid:25057339.

Rasyidah, T. I., Suhana, S., Nur-Hidayah, H., Kaswandi, M. A., \& Noah, R. M. (2014). Evaluation of antioxidant activity of Zingiber officinale (ginger) on formalin-induced testicular toxicity in rats. Journal of Medical and Bioengineering, 3(3), 149-153. http://dx.doi. org/10.12720/jomb.3.3.149-153.

Ravi Kiran, C., Chakka, A. K., Padmakumari Amma, K. P., Nirmala Menon, A., Sree Kumar, M. M., \& Venugopalan, V. V. (2013). Essential oil composition of fresh ginger cultivars from North-East India. The Journal of Essential Oil Research, 25(5), 380-387. http://dx.doi.org/ 10.1080/10412905.2013.796496.

Rhee, C. O., Park, K. H., \& Seog, H. M. (1992). Changes in quality attributes of Changpyung yeot (taffy-like foods) with storage temperature. Korean Journal of Food Science Technology, 24(5), 515-518.

Sethi, S., Dutta, A., Gupta, B. L., \& Gupta, S. (2013). Antimicrobial activity of spices against isolated food borne pathogens. International Journal of Pharmacy and Pharmaceutical Sciences, 5(1), 260-262.

Stoilova, I., Krastanov, A., Stoyanova, A., Denev, P., \& Gargova, S. (2007). Antioxidant activity of a ginger extract (Zingiber officinale). Food Chemistry, 102(3), 764-770. http://dx.doi.org/10.1016/j. foodchem.2006.06.023.

Thaipong, K., Boonprakob, U., Crosby, K., Cisneros-Zevallos, L., \& Hawkins Byrne, D. H. (2006). Comparison of ABTS, DPPH, FRAP, and ORAC assays for estimating antioxidant activity from guava fruit extracts. Journal of Food Composition and Analysis, 19(6-7), 669-675. http://dx.doi.org/10.1016/j.jfca.2006.01.003.

Tohma, H., Gülçin, İ., Bursal, E., Gören, A. C., Alwasel, S. H., \& Köksal, E. (2017). Antioxidant activity and phenolic compounds of ginger (Zingiber officinale Rosc.) determined by HPLC-MS/MS. Journal of Food Measurement and Characterization, 11(2), 556-566. http:// dx.doi.org/10.1007/s11694-016-9423-z.

Yamamoto-Ribeiro, M. M., Grespan, R., Kohiyama, C. Y., Ferreira, F. D., Mossini, S. A., Silva, E. L., Filho, B. A., Mikcha, J. M., \& Machinski, M. Jr (2013). Effect of Zingiber officinale essential oil on Fusarium verticillioides and fumonisin production. Food Chemistry, 141(3), 3147-3152. http://dx.doi.org/10.1016/j.foodchem.2013.05.144. PMid:23871071.

Yang, H. J., \& Ryu, G. H. (2010). Preparation and characterization of Jochung, a grain syrup, with apple. Journal of the Korean Society of Food Science and Nutrition, 39(1), 132-137. http://dx.doi.org/10.3746/ jkfn.2010.39.1.132. 